\title{
Complications of selective laser trabeculoplasty: a review
}

This article was published in the following Dove Press journal:

Clinical Ophthalmology

14 January 2016

Number of times this article has been viewed

Julia Song

Ophthalmology, Long Beach Memorial Medical Center, Long Beach, CA, USA

Video abstract

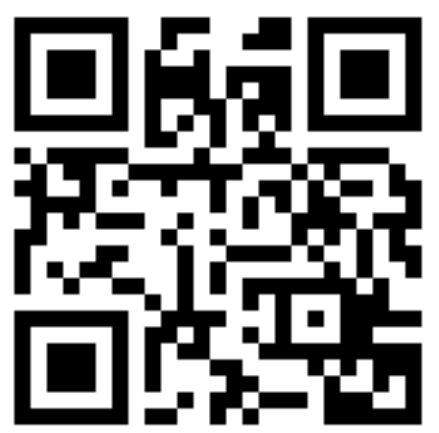

Point your SmartPhone at the code above. If you have a QR code reader the video abstract will appear. Or use:

http://youtu.be/7s8xFKrzVIf
Correspondence: Julia Song Ophthalmology, Long Beach Memorial Medical Center, 2840 Long Beach Boulevard, \#330, Long Beach,

CA 90806, USA

Tel +I 5624270700

$\mathrm{Fax}+\mathrm{I} 5624272525$

Email jsongmd@drsongvision.com
Abstract: Selective laser trabeculoplasty is a laser treatment to treat glaucoma. It was initially indicated for open-angle glaucoma but has been proven to be efficacious for various types of glaucoma. This review article summarizes the few rare complications that can be seen with selective laser trabeculoplasty. It also makes recommendations on how to avoid these problems and how to treat patients when these rare complications arise.

Keywords: SLT, glaucoma, complications

\section{Introduction}

Glaucoma is an optic neuropathy in which intraocular pressures (IOPs) that are too high for the eye can result in optic nerve damage, subsequently leading to peripheral or central visual field loss. Modes of treatment include medications, laser, or intraocular surgery.

Argon laser trabeculoplasty (ALT) was developed by Wise and Witter ${ }^{1}$ in the 1970s. It was an adjunct as well as a supplement to topical and oral medications. Although successful, ALT had several side effects, most notably elevated IOP and inflammation. It also coagulated the trabecular meshwork (TM) tissue, resulting in peripheral anterior synechiae.

Selective laser trabeculoplasty (SLT) was developed in 1999 by Latina and Park ${ }^{2}$ as an alternative to ALT. SLT is a laser treatment that can reduce IOP in patients with open-angle glaucoma (OAG). SLT has a very short pulse duration (3 ns), which is shorter than the thermal relaxation time of melanin, allowing for selective photothermolysis. Because SLT selectively targets the pigmented TM cells and has an energy level $1 \%$ of ALT, it is a gentler laser than ALT with no histologic scarring or coagulative damage to the TM, ${ }^{3,4}$ thus reducing collateral damage to surrounding tissues and making repeat treatments possible. The incidence of iritis and elevated IOP is much lower compared to ALT. ${ }^{5}$

\section{Indications}

SLT has a variable success rate $(40 \%-70 \%)$ in adults. ${ }^{6-8}$ SLT has been shown to be safe in adults, ${ }^{9}$ and the complication rate is extremely low. SLT is also safe as initial therapy in OAG and in patients with ocular hypertension. ${ }^{10}$ SLT was also found to be comparable to ${ }^{11}$ and in some reports more efficacious ${ }^{12}$ than ALT. Although SLT was initially indicated for OAG, pseudoexfoliation, and pigmentary glaucomas, SLT has been utilized for a wide variety of glaucomas. It is indicated for low-tension glaucoma, reducing not only IOP but diurnal fluctuation of IOP. ${ }^{13,14}$ SLT has also been proven to be helpful in treating steroid-induced glaucoma or as prophylaxis for 
anticipated steroid-induced glaucoma. ${ }^{15}$ It has been found to be effective in juvenile OAG patients as well. ${ }^{16}$ SLT has also been reported to be utilized after unsuccessful reduction of IOP after iridotomy, ${ }^{17}$ deep sclerectomy, ${ }^{18}$ trabectome, ${ }^{19}$ and after retinal detachment repair with silicone oil. ${ }^{20}$ It has also been reported to dissolve an iris pigment epithelial cyst. ${ }^{21}$

\section{Mechanism of action}

The mechanism of action of SLT is not fully understood, although it is believed that it is more cellular and less mechanical or thermal, ${ }^{22}$ with macrophages from the spleen recruited into the $\mathrm{TM}$ via cytokines to remove debris from the TM. ${ }^{23}$ Histological studies have demonstrated minimal coagulative or mechanical damage.,22,24 The TM following SLT was intact except for cracks in the corneoscleral sheets and a few endothelial cells with disrupted intracytoplasmic pigment granules and vacuoles. ${ }^{3,24}$ There is also evidence of TM cell division following both ALT and SLT. ${ }^{25,26}$

There is controversy whether SLT efficacy decreases with the use of concomitant prostaglandins. One study ${ }^{27}$ reported a $7 \%$ drop in IOP vs $20 \%$ drop in IOP when not taking prostaglandins. Another study ${ }^{28}$ found that the success rate of SLT was $78.6 \%$ at 1 year in patients who were on combined dorzolamide-timolol and only $50 \%$ in patients who were on prostaglandins $(P=0.041)$. Schlemm canal cells exposed to media conditioned by L cells that had been exposed to SLT or prostaglandin analogs demonstrated similar cell junction disassembly, whereas the cells exposed to nonprostaglandin analogs (brimonidine, timolol, and dorzolamide) did not show cell junction disassembly. ${ }^{29}$ This implies a similar mechanism of action between prostaglandins and SLT. The poorer success of SLT in patients on prostaglandins may suggest similar mechanisms of action of SLT and prostaglandins and that these two treatment methods may compete with one another. ALT use declined with the advent of prostaglandins for glaucoma therapy. Perhaps the decline in ALT efficacy in the 1990s was due to the minimal efficacy as a result of competition between prostaglandins and ALT (since they both share the same mechanism of action). The same process could be occurring today between prostaglandins and SLT. However, another study ${ }^{30}$ demonstrated no difference in IOP reduction between eyes that had received prostaglandins and eyes that did not receive prostaglandins.

\section{Complications of SLT}

As stated earlier, the complication rate of SLT is very low. This review will cover these complications, examples of which have been published in case reports. This review will advise on how to prevent or manage these complications. The initial SLT study ${ }^{31}$ by the US Food and Drug Administration involved 120 patients. The adverse events reported were anterior chamber inflammation in 107/120 (89\%), pain/ discomfort in 6/120 (5\%), redness in 6/120 (5\%), and IOP elevation in 7/120 (6\%) patients. In 2004, there were 13 studies that reported on SLT, its efficacy, and the side effects. Most subjects were patients with OAG or ocular hypertension.

In 2014, there were 204 studies on the topic of SLT, with increasing coverage internationally (Egypt, People's Republic of China, St Lucia, Israel, Japan, Korea). Although SLT is reportedly a relatively safe procedure, there are an increasing number of reported side effects, including elevated IOP, iritis, choroidal effusion, hyphema, macular edema, foveal burns, corneal edema, diffuse lamellar keratitis, and refractive shifts (hyperopic and myopic). In 2004, only the single SLT unit was available. Currently, there exist combination laser units, dual combination SLT and yttrium aluminum garnet (YAG) and the triple combination SLT, YAG, and Argon units. Inadvertent complications have occurred with the dual-model SLT unit, in which the SLT mode was utilized during a routine YAG capsulotomy. ${ }^{32}$

\section{Elevated IOP}

There is a low incidence of elevated IOP after SLT, which is defined as an IOP $\geq 6 \mathrm{mmHg}$ at 1 hour post-SLT. ${ }^{33}$ A study ${ }^{12}$ reported elevated IOP after ALT of $3.4 \%$ and SLT of $4.5 \%$; both were transient. In patients with pseudoexfoliation glaucoma, there was not an increased risk of IOP elevation after SLT. ${ }^{33-36}$ However, patients with pigmentary glaucoma may be at risk for high postlaser IOPs; in a case report, ${ }^{37}$ four patients undergoing SLT had elevated IOPs of $30-46 \mathrm{mmHg}$ following the treatment. All four patients were young and had heavy pigment in their TM; two had prior ALT, and one had previous trauma. The duration of IOP elevation lasted between 4 days and 3 months. Three of the four patients required trabeculectomy to control their IOPs.

\section{Iritis}

Postoperative inflammation following SLT usually occurs 2-3 days following the procedure. It has been seen in $83 \%$ of eyes undergoing SLT. The inflammation is usually transient and resolves in 5 days. Risk factors include heavily pigmented TM or a history of prior ALT. In a 6-month study, ${ }^{12}$ the number of anterior chamber cells 1 hour following SLT was significantly higher than $\operatorname{ALT}(P=0.009)$, although the amount of flare was not $(P=0.39)$. 
Bilateral anterior uveitis has been reported ${ }^{38}$ in a patient undergoing unilateral SLT oculus sinister (OS) (50 spots, $0.6 \mathrm{~mJ}, 180^{\circ}$ treatment inferiorly). There were no problems postoperative week 1 , but on postoperative week 3 , the patient reported cloudy vision oculus uterque (OU) to $6 / 12$ and 6/15 vision, with bilateral uveitis, $3+$ cell and flare bilateral posterior synechiae, corneal haze, and multiple dark spots on the endothelium.

Following treatment with prednisolone, cyclopentolate, and tropicamide $\mathrm{OU}$, the bilateral anterior uveitis resolved completely in 2 weeks. A work-up for autoimmune conditions was negative. The fact that unilateral SLT resulted in bilateral iritis supports the theory that SLT may be a systemic response. ${ }^{23}$ SLT has been reported to lower IOP in the contralateral eye. ${ }^{39,40}$

In another report, ${ }^{41}$ a patient with iritis also developed a choroidal effusion. This resolved with medical therapy.

\section{Hyphema}

Two cases of hyphema were reported. A 77-year-old female with OAG developed a hyphema 3 days following SLT, ${ }^{42}$ and this resolved completely. She had been taking intermittent oral nonsteroidal anti-inflammatory medications as well as chronic topical nonsteroidal drops, which may have been contributing factors.

Shihadeh et $\mathrm{al}^{43}$ reported hyphema that occurred during the SLT treatment in a patient with OAG. The patient underwent SLT OU but only developed the hyphema OS. This spontaneously resolved without sequelae, and the patient had good IOP control. No reports of hyphema following ALT have been found.

\section{Macular edema}

There have been reports of retinal side effects, including cystoid macular edema (CME) following SLT in a patient with preexisting pseudophakic macular edema ${ }^{44}$ steroidinduced glaucoma in a patient with diabetes ${ }^{45}$ worsening diabetic retinopathy, ${ }^{46}$ and foveal burns. ${ }^{32}$

Wechsler and Wechsler ${ }^{44}$ reported a case in which CME developed after complicated cataract surgery. The patient was treated with steroids but then developed steroid-induced IOP elevation 2 years later. The patient was then treated with $180^{\circ} \mathrm{SLT}$ and developed recurrent CME. This was treated medically with resolution of the CME.

Ha et al ${ }^{45}$ reported a 47 -year-old patient with a history of moderate nonproliferative diabetic retinopathy who presented with clinically significant macular edema oculus dexter (OD). Fluorescein angiography demonstrated leaking microaneurysms that were treated with a focal laser photocoagulation. The patient also received a posterior subtenon's triamcinolone injection OD $(40 \mathrm{mg} / \mathrm{mL})$ with almost complete resolution of his macular thickening. Seven months later, his vision was $6 / 6$, but optical coherence tomography (OCT) demonstrated mild recurrent CME OD. The IOP OD was $37 \mathrm{mmHg}$ despite the two glaucoma medications, so SLT OD was performed $\left(0.9 \mathrm{~mJ}, 100\right.$ spots, $\left.360^{\circ}\right)$. One week later, the IOP dropped to $16 \mathrm{mmHg}$, but the patient stated that his vision worsened, and OCT demonstrated marked macular edema. He was prescribed topical ketorolac qid (four times a day) for 8 weeks and topical dexamethasone qid for 2 weeks.

Although his steroid-induced IOP was controlled with SLT, his macular edema was exacerbated by the SLT.

Other cases demonstrated worsening CME following SLT in a patient with diabetes and in another patient with a branch retinal vein occlusion. A 68-year-old white female with diabetes and OAG (on maximal medications) underwent uncomplicated cataract extraction OU in $2009 .{ }^{46}$ She had mild diabetic retinopathy OU with scattered microaneurysms but no foveal pathology. She underwent bilateral SLT 1 week apart (OS first, followed by OD). She then developed bilateral CME. After treatment with topical prednisolone and ketorolac, the CME OD resolved in 12 weeks; CME OS resolved in 4 months.

The other patient was a 79-year-old white female with a branch retinal vein occlusion OS without macular edema. ${ }^{46}$ She underwent uncomplicated cataract extraction OS in 2009. She was treated with SLT OU $360^{\circ}$, 1 week apart. One month later, she developed CME OS. Her anterior chamber was quiet. Dilated examination revealed a few microaneurysms and telangectiasias near the fovea, which were unchanged. OCT OS demonstrated CME $(421 \mu \mathrm{m})$. This was treated with topical ketorolac twice daily. Her visual acuity returned to baseline in 1 month.

\section{Foveal burn}

SLT performed correctly has not been reported to cause foveal burns. However, there is one case ${ }^{32}$ in which SLT was accidentally utilized during a routine scheduled YAG posterior capsulotomy. A YAG capsulotomy with $58 \mathrm{~mJ}$ on a single pulse setting was performed. The next day, the patient's vision was count fingers OS. The presumed diagnosis was CME, so ketorolac OS qid was prescribed. The patient developed a foveal scar with reduced vision to count fingers OS. The dual YAG-SLT unit (Duet) had been utilized. Upon investigation 3 days later, it was discovered 
that the SLT mode was on during the YAG capsulotomy. The operator had discovered the error and changed the laser back to the correct (YAG) mode. The settings of the SLT were unknown. At the 1-year follow-up, the patient had not recovered any vision. Risk management was involved, and steps were taken for extensive laser training and safety measures. It was recommended that all users of the dual-laser systems reset the function at each procedure, regardless of previous settings.

\section{Corneal haze}

It is not surprising that corneal changes have been reported following SLT. Studies have demonstrated corneal endothelial changes within 1-2 hours of SLT. ${ }^{47}$ One hour following SLT, nearly all of the 10 patients who underwent $180^{\circ} \mathrm{SLT}$ had corneal changes on slit-lamp examination. These changes were clinically insignificant and reversible. There was no change in endothelial cell count or visual acuity. SLT induces changes in the corneal endothelium ZO-1 tight junctions in cadaveric human corneas, much as it induces changes in the TM cells. ${ }^{48}$

The incidence of corneal edema after SLT is $0.8 \%{ }^{49}$ In prospective study ${ }^{50}$ of eleven eyes of 66 patients who underwent $360^{\circ}$, there was a transient decrease in endothelial cell count $(P=0.0004)$ and central corneal thickness (CCT) $(P=0.2)$. These returned to baseline at 1 month. Corneal stromal haze is a rare but serious side effect. To date, there are eight reported cases of SLT-induced keratitis with a hyperopic shift. ${ }^{51-56}$ In these cases, most patients were high myopes. There was no preexisting history of herpes labialis or iritis.

In addition to hyperopic shifts as in the cases above, one case of a myopic shift after SLT in a patient has been reported. ${ }^{57}$ A 48 -year-old white female had a history of juvenile OAG at age 20 years. She had previously undergone ALT in both eyes with minimal success. She underwent trabeculectomy with mitomycin-C in the OS in 1994, at age 27 years and had done well. Her OD was prescribed four topical glaucoma medications: dorzolamide-timolol, brimonidine, and latanoprost.

Preoperatively, the patient's visual acuity with correction was 20/30 pinhole, no improvement OD, and 20/20 OS. Her preoperative refraction was $-7.25-0.75 \times 124$ OD and $-5.75-2.25 \times 44$ OS. Her preoperative IOPs were $23 \mathrm{mmHg}$ OD on four topical medications and $13 \mathrm{mmHg}$ OS without medications. Dilated examination revealed enlarged optic nerve cupping of 0.9 in both eyes, with normal vessels, maculae, and periphery. Her preoperative central corneal thicknesses (CCTs) are 508 and $505 \mu \mathrm{m}$, respectively.
A repeat visual field test revealed worsening visual field defects OD. She elected to undergo SLT OD, with settings of $0.8 \mathrm{~mJ}, 360^{\circ}$, and 102 spots. Postoperatively, her IOP was $14 \mathrm{mmHg}$.

One week later, the patient reported foggy vision and photosensitivity. Her refraction OD demonstrated a 4-diopter myopic shift of $-11.00-0.75 \times 135$ (visual acuity had diminished from 20/20 to 20/30-2). Her IOP was $15 \mathrm{mmHg}$. There was rare cell and flare in the anterior chamber. Fundus examination revealed no vitreous cell or macular edema. CCTs were unchanged. Three weeks after SLT, her refraction was unchanged. A-scan ultrasound revealed axial lengths of $26.4 \mathrm{~mm}$ OD and $26.0 \mathrm{~mm}$ OS. Her anterior chamber depths were $3.24 \mathrm{~mm}$ OD ( $0.15 \mathrm{~mm}$ shallower compared to OS $)$ and $3.39 \mathrm{~mm}$ OS. Her lens thicknesses were symmetrical at 4.20 and $4.23 \mathrm{~mm}$, respectively.

Five weeks following SLT OD, her refraction normalized back to baseline. Her IOPs were $17 \mathrm{mmHg}$ OD and $13 \mathrm{mmHg}$ OS. Her anterior chamber depth deepened $0.22 \mathrm{~mm}$ back to baseline at $3.46 \mathrm{~mm}$; her axial lengths and lens thickness remained unchanged. Like the patients with lamellar keratitis and hyperopic shift, this patient had high myopia. A-scan ultrasonography revealed shallowing of the anterior chamber and increased thickness of the anteroposterior dimension of the cataract with myopic shift. These findings resolved in 3 weeks.

\section{Discussion}

To understand the complications, one must have an understanding of how SLT works. SLT theoretically involves cytokine production from the TM. These cytokines include interleukin-alpha (IL-1 $\alpha$ ), interleukin-1 beta (IL-1 $\beta$ ), and tumor necrosis factor-alpha (TNF- $\alpha) .{ }^{58,59}$ The result is recruitment of macrophages from the spleen that phagocytose debris in the TM extracellular matrix. There is an increase in lipid peroxidase and a decrease in free radical scavenging superoxide dismutase and glutathione $S$-transferase in aqueous fluid, suggesting free oxygen radical formation that may account for the postoperative inflammation. ${ }^{54}$ Wood et al ${ }^{60}$ demonstrated that SLT causes TM cell death. Other laser treatments, including diode laser cyclophotocoagulation, have been found to increase central corneal thickness, ${ }^{61}$ which may represent corneal endothelial decompensation. A comparison of SLT and ALT found that inflammation was greater in SLT patients (possibly due to the greater spot size), which could affect a larger surface area of tissue (the ciliary body and the iris root), thus possibly accounting for the spread of inflammation to the cornea. 
In a study by Song et $\mathrm{al},{ }^{55}$ OCT demonstrated diffuse corneal edema with mild aqueous cell and flare. Over the first 7 days, the corneal haze became more defined centrally. The first OCT analysis at 3 weeks following SLT showed marked corneal thinning with stromal haze sparing the posterior corneal stroma. Flattening of the anterior corneal curvature was grossly evident on OCT and coincided with a large hyperopic shift in refraction. Sequential OCT analysis over the next several months showed a gradual increase in corneal thickness along with a qualitative reduction in corneal stromal haze. The thickness of the corneal epithelial layer remained unchanged during this period, and the corneal thickness changes appeared to be only in the stroma.

The findings suggest changes in the corneal stroma with no endothelial involvement. The mechanism appears to be that of stromal collagen damage leading to an inflammatory reaction and removal of damaged collagen. This phase would correspond to corneal haze and stromal thinning. The inflammatory phase is followed by the laying down of additional collagen by keratocytes, leading to corneal thickening. How SLT treatment causes corneal stromal collage damage is unknown. Possibilities would include direct light damage, indirect thermal damage, or chemical damage during treatment or in the early postoperative period. Contrary to the theory that SLT-induced corneal edema involves mainly the stroma, Leahy et $a{ }^{48}$ has reported SLT-induced changes in the corneal endothelium $\mathrm{ZO}-1$ tight junctions in cadaveric human corneas, much as it induces changes in the TM cells.

Other reported side effects of SLT can help elucidate its mechanism of action. Aykan et al ${ }^{62}$ reported increased ciliary body and iris thicknesses within the first month of treatment. This is in line with the increased inflammation seen with SLT compared to ALT. Following ALT, the greatest inflammatory response was 48 hours posttreatment, implying that the TM can synthesize prostaglandins that act as mediators of inflammation. Interestingly, the thickest area of the ciliary body was in the superior quadrant, away from the area treated (inferior angle), implying that the SLT's biologic response affected areas not directly irradiated by SLT. This may explain why this patient's cornea was affected by SLT although the laser does not directly target the corneal endothelium. Another theory is that the inflammatory cascade induced by SLT could have reactivated an occult herpes simplex infection, particularly in those patients on concomitant topical prostaglandins. In this case, the patient was taking latanoprost, but he denied any history of herpes keratitis or infection.
Upregulation of metalloproteinases (MMP), particularly MMP-9, has been associated with pseudophakic corneal edema. ${ }^{63}$ SLT has been known to increase the amount of MMP in the aqueous humor. MMP-2 is the major metalloproteinase secreted after laser therapy and is inhibited by tissue inhibitor of metalloprotineases (TIMP)-2. In pseudoexfoliative glaucoma, the enzyme balance between MMP-2 and TIMP-2, already impaired by the pseudoexfoliative syndrome, is seriously altered even compared with OAG. The ratio of MMP-2 to TIMP-2 after SLT is increased in pseudoexfoliative glaucoma. Overexpression of matrix MMP by resident corneal cells has been shown to impede re-epithelialization after some types of corneal injury. ${ }^{64}$ This may partially account for our patient's corneal pathology.

It is helpful to identify risk factors that predispose to various side effects. Elevated postoperative IOP can occur in eyes with heavy pigmentation, previous ALT, or multiple medications. Previous corneal haze has been reported in patients with possible predisposing conditions, such as prior laser-assisted in situ keratomileusis (LASIK) $)^{51-54}$ or a history of herpes labialis. Proposed mechanisms of corneal stromal inflammation may involve migration of monocytesmacrophages into the corneal stroma. A study by Hong et $\mathrm{a}^{65}$ demonstrated that cytokines IL- 1 and TNF- $\alpha$ activated monocytes chemotactic and activating factor and granulocyte colony-stimulating factor. Patients taking bimatoprost have significantly higher levels of IL- $1 \beta$ and TNF- $\alpha$ in their tears. ${ }^{66}$ Our patient was taking a topical prostaglandin at the time of his SLT treatment, which may have contributed to more inflammation. Furthermore, if prostaglandins and SLT have a similar mechanism of action, perhaps the inflammatory mediators were directed to the cornea rather than the TM, accounting for his corneal side effects.

Ophthalmologists should be aware of these potential complications after SLT. Patients should be warned of these possible complications. The author recommends performing unilateral SLT. However, if the patient has had successful SLT in the past and needs a repeat SLT, bilateral SLT may be performed if clinically indicated.

If patient does develop corneal stromal edema and haze, immediate hourly topical steroids can be initiated if there is no contraindication.

To avoid inadvertent SLT into the fovea, care should be taken when using the dual combination units (YAG-SLT) or triple combination units (YAG-SLT-Argon). Precautions should be taken to ascertain that the correct laser setting is utilized. Alternatively, individual laser units can be utilized in lieu of combination units to avoid these errors. For patients 
who may be predisposed to complications, lower laser settings can be used.

\section{Conclusion}

Although SLT is relatively safe and efficacious, complications do exist, and some can be serious. These include high IOP, iritis, hyphema, choroidal effusion, macular edema, foveal burns with macular scars, corneal haze, and shifts in refractive error (both myopic and hyperopic). Physicians and patients should be aware of these potentially visionthreatening side effects. More studies are needed to identify risk factors for the development of complications. Those patients with identifiable risk factors can be counseled about the risk of side effects.

\section{Disclosure}

The author reports no conflicts of interest in this work.

\section{References}

1. Wise JB, Witter SL. Argon laser therapy for open-angle glaucoma. A pilot study. Arch Ophthalmol. 1979;97(2):319-322.

2. Latina MA, Park C. Selective targeting of trabecular meshwork cells: in vitro studies of pulsed and CW laser interactions. Exp Eye Res. 1995;60(4):359-372.

3. Kramer TR, Noecker RJ. Comparison of the morphological changes after selective laser trabeculoplasty and argon laser trabeculoplasty in human eye bank eyes. Ophthalmology. 2001;108(4):773-779.

4. Glaucoma Laser Trial Research Group. The glaucoma laser trial. Results of argon laser trabeculoplasty versus topical medicines. Ophthalmology. 1990;97(11):1403-1413.

5. Ayala M, Landau Hoqbeck I, Chen E. Inflammation assessment after selective laser trabeculoplasty (SLT) treatment. Acta Ophthalmol. 2011; 89(4):E306-E309.

6. Shibata M, Sugiyama T, Ishida O, et al. Clinical results of selective laser trabeculoplasty in open angle glaucoma in Japanese eyes: comparison of 180 degree with 360 degree SLT. J Glauc. 2012;21(1):17-21.

7. Tang M, Fu Y, Fu MS, et al. The efficacy of low-energy selective laser trabeculoplasty. Ophthalmic Surg Lasers Imaging. 2001;42(1): 59-63.

8. Song J, Lee PP, Epstein DL, et al. High failure rate of 180 degree selective laser trabeculoplasty. J Glaucoma. 2005;14(5):400-408.

9. Liu Y, Birt CM. Argon versus selective laser trabeculoplasty in younger patients: 2-year results. J Glaucoma. 2012;21(2):112-115.

10. Melamed S. Selective laser trabeculoplasty in uncontrolled pseudoexfoliation glaucoma. Ophthalmic Surg Lasers Imaging. 2011;42(5): 390-393.

11. Juzych MS, Chopra V, Banitt MR, et al. Comparison of long-term outcomes of selective laser trabeculoplasty versus argon laser trabeculoplasty in open-angle glaucoma. Ophthalmology. 2004;111(10): 1853-1859.

12. Damji K, Shah K, Rock W, Bains H, Hodge W. Selective laser trabeculoplasty vs argon laser trabeculoplasty: a prospective randomized clinical trial. Br J Ophthalmol. 1999;83(6):718-722.

13. Tojo N, Oka M, Miyakoshi A, Ozaki H, Hayashi A. Comparison of fluctuations of intraocular pressure before and after selective laser trabeculoplasty in normal-tension glaucoma patients. J Glauc. 2014;23(8): e138-e143.

14. Lee JW, Gangwani RA, Chan JC, Lai JS. Prospective study on the efficacy of treating normal tension glaucoma with a single session of selective laser trabeculoplasty. J Glauc. 2015;24(1):77-80.
15. Bozkurt E, Kara N, Yazici AT, et al. Prophylactic selective laser trabeculoplasty in the prevention of intraocular pressure elevation after intravitreal triamcinolone acetonide injection. Am J Ophthalmol. 2011;152(6):976-981.

16. Song J, Song A, Palmares T, Song M. Selective laser trabeculoplasty success in pediatric patients with glaucoma: two case reports. $J$ Med Case Reports. 2013;7:198.

17. Ho CL, Lai JS, Aquino MV, et al. Selective laser trabeculoplasty for primary angle closure with persistently elevated intraocular pressure after iridotomy. J Glauc. 2009;18(7):563-566.

18. Baykara M, Hamidi NA, Akova-Budak B, Sabur H, Poroy C. Early results of selective laser trabeculoplasty in patients resistant to deep sclerectomy. Eur J Ophthalmol. 2014;24(3):371-374.

19. Töteberg-Harms M, Rhee DJ. Selective laser trabeculoplasty following failed combined phacoemulsification cataract extraction and ab interno trabeculectomy. Am J Ophthalmol. 2013;156(5):936-940.

20. Alkin Z, Satana B, Ozkaya A, et al. Selective laser trabeculoplasty for glaucoma secondary to emulsified silicone oil after pars plana vitrectomy: a pilot study. Biomed Res Int. 2014;13:469163.

21. Guler M, Bilgin B, Reyhan AL. Treatment of peripheral pigment epithelium iris cyst with SLT laser. Optom Vis Sci. 2013;90(4): 106-109.

22. Stein JD, Challa P. Mechanisms of action and efficacy of argon laser trabeculoplasty and selective laser trabeculoplasty. Curr Opin Ophthalmol. 2007;18(2):140-145.

23. Alvarado J, Katz L, Trivedi S, Shifera A. Monocyte modulation of aqueous outflow and recruitment to the trabecular meshwork following selective laser trabeculoplasty. Arch Ophthalmol. 2010;128(6): 731-737.

24. Cvenkel B, Hvala A, Drnovsek-Olup B, Gale N. Acute ultrastructural changes of the trabecular meshwork after selective laser trabeculoplasty and low power argon laser trabeculoplasty. Lasers Surg Med. 2003;33(3):204-208.

25. Bylsma SS, Samples JR, Acott TS, Van Buskirk EM. Trabecular cell division after argon laser trabeculoplasty. Arch Ophthalmol. 1988; 106(4):544-547.

26. Dueker DK, Norberg M, Johnson DH, Tschumper RC, Feeney-Burns L. Stimulation of cell division by argon and Nd:YAG laser trabeculoplasty in cynomolgus monkeys. Invest Ophthalmol Vis Sci. 1990;31(1): 115-124.

27. Latina MA, Gulati V. Selective laser trabeculoplasty: stimulating the meshwork to mend its ways. Int Ophthalmol Clin. 2004;44(1): 93-103.

28. Kara N, Altan C, Satana B, et al. Comparison of selective laser trabeculoplasty success in patients treated with either prostaglandin or timolol/dorzolamide fixed combination. JOcul Pharmacol Ther. 2011; 27(4):339-342

29. Alvarado JA, Iguchi R, Martinez J, Trivedi S, Shifera AS. Similar effects of selective laser trabeculoplasty and prostaglandin analogs on the permeability of cultured Schlemm canal cells. Am J Ophthalmol. 2010;150(2):254-264.

30. Ayala M, Chen E. The influence of topical prostaglandin analogues in inflammation after selective laser trabeculoplasty treatment. $J$ Ocul Pharmacol Ther. 2012;28(2):118-122.

31. Latina MA, Sibayan SA, Shin DH, Noecker RJ, Marcellino G. Q-switched 532-nm Nd:YAG laser trabeculoplasty (selective laser trabeculoplasty): a multicenter, pilot, clinical study. Ophthalmology. 1998; 105:2082-2090.

32. Liyanage SE, Kumaran N, De Alwis D. Macular burns resulting from the accidental use of selective laser trabeculoplasty mode during a laser capsulotomy. Br J Ophthalmol. 2014;98:141-142.

33. Koucheki B, Hashemi H. Selective laser trabeculoplasty in the treatment of open-angle glaucoma. J Glaucoma. 2012;21(1):65-70.

34. Shazly TA, Smith J, Latina MA. Long-term safety and efficacy of selective laser trabeculoplasty as primary therapy for the treatment of pseudoexfoliation glaucoma compared with primary open-angle glaucoma. Clin Ophthalmol. 2010;5:5-10. 
35. Goldenfeld M, Geyer O, Segev E, Kaplan-Messas A, Melamed S. Selective laser trabeculoplasty in uncontrolled pseudoexfoliation glaucoma. Ophthalmic Surg Lasers Imaging. 2011;42(5):390-393.

36. Ayala M, Chen E. Comparison of selective laser trabeculoplasty (SLT) in primary open angle glaucoma and pseudoexfoliation glaucoma. Clin Ophthalmol. 2011;5:1469-1473.

37. Harasymowycz P, Papamatheakis D, Latina M, De Leon M, Lesk MR, Damji KF. Selective laser trabeculoplasty (SLT) complicated by intraocular pressure elevation in eyes with heavily pigmented trabecular meshworks. Am J Ophthalmol. 2005;139:1110-1113.

38. Koktekir BE, Gedik S, Bakbak B. Bilateral severe anterior uveitis after unilateral selective laser trabeculoplasty. Clin Experiment Ophthalmol. 2013;41(3):305-307.

39. McIlraith I, Strasfeld M, Colev G, Hutnik CM. Selective laser trabeculoplasty as initial and adjunctive treatment for open-angle glaucoma. J Glaucoma. 2006;15(2):124-130.

40. Rhodes KM, Weinstein R, Saltzmann RM, et al. Intraocular pressure reduction in the untreated fellow eye after selective laser trabeculoplasty. Curr Med Res Opin. 2009;25(3):787-796.

41. Kim DY, Singh A. Severe iritis and choroidal effusion following selective laser trabeculoplasty. Ophthalmic Surg Lasers Imaging. 2008;39(5): 409-411.

42. Rhee D, Krad O, Pasquale LR. Hyphema following selective laser trabeculoplasty. Ophthalmic Surg Lasers Imaging. 2009;40(5):493-494.

43. Shihadeh W, Ritch R, Liebman J. Hyphema occurring during selective laser trabeculoplasty. Ophthalmic Surg Laser Imaging. 2006;37: 432-433.

44. Wechsler DZ, Wechsler IB. Cystoid macular oedema after selective laser trabeculoplasty. Eye (Lond). 2010;24(6):1113.

45. Ha JH, Bowling B, Chen SD. Cystoid macular oedema following selective laser trabeculoplasty in a diabetic patient. Clin Experiment Ophthalmol. 2014;24(2):200-201.

46. Wu ZQ, Huang J, Sadda S. Selective laser trabeculoplasty complicated by cystoid macular edema: report of two cases. Eye Sci. 2012;27: 193-197.

47. White AJ, Mukherjee A, Hanspal I, Sarkies NJ, Martin KR, Shah P. Acute transient corneal endothelial changes following selective laser trabeculoplatsy. Clin Experiment Ophthalmol. 2013;41(5):435-441.

48. Leahy K, Sarris M, Di Girolamo N, et al. Investigation of corneal endothelial changes post selective laser trabeculoplasty. Invest Ophthalmol Vis Sci. 2014;55(13):6162.

49. Latina MA, Tumbocon JA. Selective laser trabeculoplasty: a new treatment option for open angle glaucoma. Curr Opin Ophthalmol. 2002;13(2):94-96.

50. Lee JW, Chan JC, Chang RT, et al. Corneal changes after a single session of selective laser trabeculoplasty for open-angle glaucoma. Eye. 2014;28:47-52.

51. Regina M, Bunya VY, Orlin SE, Ansari H. Corneal edema and haze after selective laser trabeculoplasty. J Glauc. 2011;20(5):327-329.

Clinical Ophthalmology

\section{Publish your work in this journal}

Clinical Ophthalmology is an international, peer-reviewed journal covering all subspecialties within ophthalmology. Key topics include: Optometry; Visual science; Pharmacology and drug therapy in eye diseases; Basic Sciences; Primary and Secondary eye care; Patient Safety and Quality of Care Improvements. This journal is indexed on
52. Moubayed SP, Hamid M, Choremis J, Li G. An unusual finding of corneal edema complicating selective laser trabeculoplasty. Can J Ophthalmol. 2009;44:337-378.

53. Holz H, Pirouzian A. Bilateral diffuse lamellar keratitis following consecutive selective laser trabeculoplasty in a LASIK patient. J Cataract Refract Surg. 2010;36:847-849.

54. Marquis R. Keratitis and hyperopic refractive shift Induced by SLT. Glaucoma Today. 2010;18-22.

55. Song J, Yu D, Song A, Palmares T, Song HS, Song M. Corneal thinning and opacity following selective laser trabeculoplasty: a case report. Brit J Med Res. 2014;4(1):1

56. Jun J, Ansari H, Regina M, Moster M. Corneal complications associated with selective laser trabeculoplasty. Poster presented at: American Glaucoma Society Meeting, 2012, New York, NY.

57. Song J, Song A, Palmares T, Song M. Myopic shift following selective laser trabeculoplasty: a case report. Brt J Med Med Res. 2014;4(4): 1008-1013.

58. Bradley J, Anderssohn A, Colvis C, et al. Mediation of laser trabeculoplasty-induced matrix metalloproteinase expression by IL-1b and TNF alpha. Invest Ophthalmol Vis Sci. 2000;41(2):422-430.

59. Guzey M, Vural H, Satici A, et al. Increase of free oxygen radicals in aqueous humor induced by selective Nd: YAG laser trabeculoplasty in the rabbit. Eur J Ophthalmol. 2001;11(1):47-52.

60. Wood J, Plunkett M, Previn V, Chidlow G, Casson RJ. Rapid and delayed death of cultured trabecular meshwork cells after selective laser trabeculoplasty. Lasers Surg Med. 2010;42(4):326-337.

61. Macdonald J, Geroski D, Edelhauser H. Effect of inflammation on the corneal endothelial pump and barrier. Curr Eye Res. 1987;6(9): 1125-1132.

62. Aykan U, Salcan I, Yildirim O, Ersanli D. Selective laser trabeculoplasty induced changes in the thickness of ciliary body and iris evaluated by ultrasound biomicroscopy. Graefes Arch Clin Exp Ophthalmol. 2011; 249(6):887-894.

63. Fini E, Parks WC, Rinehart WB, et al. Role of matrix metalloproteinases in failure to re-epithelialize after corneal injury. Am J Pathol. 1996;149(4): 1287-1302.

64. Shoshani Y, Pe'er J, Doviner V, Frucht-Pery J, Solomon A. Increased expression of inflammatory cytokines and matrix metalloproteinases in pseudophakic corneal edema. Invest Ophthalmol Vis Sci. 2005;46(6): 1940-1947.

65. Hong J, Liu J, Lee J, et al. Pro inflammatory chemokine induction in keratocytes and inflammatory cell infiltration into the cornea. Invest Ophthalmic Vis Sci. 2001;42(12):2795-2803.

66. Malvitte L, Montange T, Vejux A, et al. Measurement of inflammatory cytokines by multitudinous assay in tears of patients with glaucoma topically treated with chronic drugs. Br J Ophthalmol. 2007;91(1) 29-32
PubMed Central and CAS, and is the official journal of The Society of Clinical Ophthalmology (SCO). The manuscript management system is completely online and includes a very quick and fair peer-review system, which is all easy to use. Visit http://www.dovepress.com/ testimonials.php to read real quotes from published authors. 